\title{
PREDIKSI FINANCIAL DISTRESS PADA PERUSAHAAN TRANSPORTASI LAUT YANG GO PUBLIC DI BURSA EFEK INDONESIA
}

\author{
Jumaizi \\ Universitas Maritim AMNI Semarang \\ e-mail: jumaizi10@gmail.com \\ Eliya Tuzaka \\ Universitas Maritim AMNI Semarang \\ e-mail : eliyatuzaka01@gmail.com
}

\begin{abstract}
ABSTRAK
Tujuan dari penelitian ini adalah untuk mengetahui gejala masalah keuangan dan untuk melihat kemungkinan terjadinya financial distress pada perusahaan jasa transportasi laut yang terdaftar di Bursa Efek Indonesia. Terdapat enam perusahaan jasa transportasi laut yang dijadikan sampel dalam penelitian ini yang diantaranya telah diprediksi mengalami financial distress. Mereka adalah PT. Humpuss Intermoda Transportasi, PT. Indo Straits, PT. Rukun Raharja, PT. Samudera Indonesia, PT. ICTSI Jasa Prima, dan PT. Pelayaran Tempura Emas, pada periode 2018 - 2019. Penelitian ini menggunakan model analisis Altman Z" Emerging Market Score sebagai alat analisisnya dimana terbagi dalam tiga kondisi yaitu kondisi sehat, rawan, dan financial distress. Hasil penelitian membuktikan bahwa dari keenam perusahaan yang berada pada kondisi financial distress dinyatakan lebih dominan, dan lainnya juga berpotensi mengalami financial distress. Hanya satu perusahaan yang berada pada kondisi keuangan yang sehat yaitu PT. Rukun Raharja, Tbk. Sehingga, perusahaan perlu meningkatkan dan memperbaiki kinerja keuangan mereka untuk mencegah resiko kebangkrutan.
\end{abstract}

Kata kunci: Financial Distress, Perusahaan Jasa Transportasi Laut, Z” Emerging Market Score

\begin{abstract}
The purpose of this study was to determine the symptoms of financial problems and to see the possibility of financial distress in sea transportation service companies listed on the Indonesia's Stock Exchange. There are six sea transportation service companies that are sampled in this study, some of which have been predicted to financial distress. They are PT. Humpuss Intermoda Transportasi, PT. Indo Straits, PT. Rukun Raharja, PT. Samudera Indonesia, PT. ICTSI Jasa Prima, and PT. Pelayaran Tempura Emas, in the 2018 - 2019 period. This study uses the Altman Z" Emerging Market Score analysis model as an analytical tool which is divided into three conditions, namely healthy, vulnerable, and financial distress conditions. From the results of the study, it has been proven that of the six companies in financial distress, they are declared more dominant, and others have the potential to experience financial distress. Only one company is in a healthy financial condition, namely PT. Rukun Raharja, Tbk. Thus, companies need to improve and fix their financial performance to prevent the risk of bankruptcy.
\end{abstract}

Keywords: Financial Distress, Sea Transportation Service Company, Z" Emerging Market Score 


\section{Pendahuluan}

Masyarakat Ekonomi ASEAN (ASEAN Economic Community) adalah salah satu keputusan Bali Concord II yang mensyaratkan sebelum 2015 Asia Tenggara akan menjadi satu pasar tunggal dan basis produksi. Artinya, sebelum 2015 semua rintangan perdagangan akan diliberalisasi dan deregulasi semua arus perdagangan dibebaskan dari biaya tarif yang selama ini menjadi penghalang perdagangan dan implementasi proteksionisme. Dengan disahkan dan disepakatinya hasil Bali Concord II tersebut maka otomatis Indonesia akan menghadapi fenomena pasar bebas, dimana barang-barang import akan mudah masuk ke pasar Indonesia dan ikut bersaing dengan produk lokal Indonesia sendiri, oleh karenanya sebagai salah satu kesiapan untuk menyongsong MEA dimana semakin bersaingnya pasar ekonomi Indonesia, tidak hanya pesaing - pesaing lokal namun juga pesaing dari luar maka diperlukan adanya pendeteksian financial distress sebagai Early Warning System (tanda peringatan awal) pada perusahaan agar dapat mempersiapkan langkah - langkah untuk mencegah terjadinya resiko kebangkrutan.

Banyaknya pesaing - pesaing yang masuk dari luar, semakin bersaing pula produk dan jasa yang ditawarkan sehingga kemungkinan terjadinya financial distress bahkan resiko kebangkrutan pada perusahaan - perusahaan atau pelaku ekonomi di Indonesia akan semakin terbuka lebar. Sebagai pencegah atau untuk meminimalisir terjadinya hal yang tidak diinginkan maka adanya informasi suatu perusahaan mengalami Financial Distress sebagai Early Warning sangat dibutuhkan. Platt dan Platt (2002) mengemukakan terdapat 3 kegunaan dari adanya informasi financial distress: 1) Dapat mempercepat tindakan manajemen untuk mencegah masalah sebelum terjadinya kebangkrutan. 2). Pihak manajemen dapat mengambil tindakan merger atau take over agar perusahaan lebih mampu untuk membayar hutang dan mengelola perusahaan dengan lebih baik. 3). Memberikan tanda peringatan awal adanya kebangkrutan pada masa yang akan datang (Early Warning System).

Beberapa peneliti yang memprediksi kondisi financial distress, Sasivimol Meeampol (2014) menyatakan dalam bahwa model altman secara menyeluruh dapat memprediksi tanda adanya kebangkrutan, model yang digunakan adalah Emerging Market Score Altman. Didukung oleh Coelho Myles (2014). Sedangkan Mu-Yen Chen, 2011, menunjukkan bahwa Particle Swarm Optimization (PSO) yang terintegrasi dengan pendekatan SVM (PSO-SVM) dapat dipertimbangkan untuk memprediksi potensi financial distress. Michael Haseley (2012) membandingkan kemampuan prediksi dari Altman (1968) dan Springate (1978) model Analisis Diskriminan Ganda tentang prediksi kebangkrutan. Sampel dari 30 perusahaan bangkrut dan 30 perusahaan pelarut diambil dari database di Bursa Efek Thailand yang berkisar dari tahun 2006-2012. Hasil penelitian menunjukkan bahwa sementara kedua model menunjukkan akurasi prediksi pada berbagai tingkat selama jangka waktu yang dipelajari, tidak ada model yang terbukti secara statistik lebih baik.

Penggunaan metode Altman Z-Score dapat kita review bersama dari jatuhnya perusahaan otomotif raksasa Amerika Serikat General Motor yang berimbas pada penutupan beberapa perusahaan di berbagai negara, termasuk di Indonesia yang kini masi hangat menjadi bahan perbincangan dalam dunia bisnis. Hal tersebut merupakan salah satu bukti keberhasilan Z-Score Altman dalam memprediksi kebangkrutan suatu perusahaan (america'smarkets.usatoday.com, 2014) walaupun sangat kontradiksi dengan pendapat Wesley R. Gray, pada Academic Research Recap, Architect Academic Insight (2011) yang memberi himbauan agar berhenti menggunakan Altman Z-Score untuk memprediksi Financial Distress dan melihat kinerja saham dikarenakan kurang akuratnya model analisis Altman Z-Score tersebut.

Fungsi dan kebijakan manajemen keuangan memberikan pemahaman bahwa manajemen keuangan adalah untuk memaksimalkan nilai perusahaan dengan menekan arus peredaran uang agar terhindar dari hal-hal yang tidak diinginkan, dimana kondisi kondisi tersebut salah satunya adalah financial distress. Kondisi financial distress perusahaan didefinisikan sebagai kondisi di mana hasil operasi perusahaan tidak cukup untuk memenuhi kewajiban perusahaan (Insolvency), dimana Insolvency dapat dibedakan dalam 2 kategori, (Emery, Finnery, Stowe, 2004), yaitu Technical Insolvency yang bersifat sementara dan munculnya karena perusahaan kekurangan kas untuk 
memenuhi kewajiban-kewajiban jangka pendek. Sedangkan Bankruptcy Insolvency bersifat lebih serius dan munculnya ketika total nilai hutang melebihi nilai total aset perusahaan atau nilai ekuitas perusahaan negatif. Supardi, (2003) memberikan arti, kebangkrutan sebagai kegagalan perusahaan dalam menjalankan operasi perusahaan untuk menghasilkan laba.

Menurut Hanafi (2009) Kebangkrutan merupakan kesulitan keuangan jangka pendek bersifat sementara dan belum begitu parah. Tetapi kesulitan semacam ini bila tidak ditangani bisa berkembang menjadi kesulitan tidak solvabel. Menurut Toto (2011) kebangkrutan merupakan kondisi dimana perusahaan tidak mampu lagi untuk melunasi kewajibannya. Kondisi ini biasanya tidak muncul begitu saja di perusahaan, ada indikasi awal dari perusahaan tersebut yang biasanya dapat dikenali lebih dini kalau laporan keuangan dianalisis secara lebih cermat dengan suatu cara tertentu. Rasio keuangan dapat digunakan sebagai indikasi adanya kebangkrutan di perusahaan. Berdasarkan beberapa pendapat para ahli tersebut, maka kebangkrutan dalam penelitian ini merupakan kondisi perusahaan yang tidak stabil dalam menjalankan usahanya dikarenakan ketidakmampuan dalam memenuhi kewajibannya sehingga mengakibatkan penurunan profitabilitas. Kebangkrutan bisa diukur dengan menggunakan rasio keuangan perusahaan. Sedangkan menurut Altman (1968) financial distress digolongkan ke dalam empat istilah umum,yaitu:

\section{a. Economic Failure}

Economic Failure terjadi ketika pendapatan perusahaan tidak dapat menutup total biaya termasuk biaya modal. Usaha yang mengalami hal tersebut dapat meneruskan operasinya sepanjang kreditur berkeinginan untuk menyediakan tambahan modal dan pemilik dapat menerima tingkat pengembalian (return) di bawah tingkat bunga pasar.

\section{b. Business Failure}

Business Failure seringkali digunakan untuk menggambarkan berbagai macam kondisi bisnis yang tidak memuaskan. Business Failure mengacu pada sebuah perusahaan berhenti beroperasi karena ketidakmampuannya untuk menghasilkan keuntungan atau mendatangkan penghasilan yang cukup untuk menutupi pengeluaran. Sebuah bisnis yang menguntungkan dapat gagal jika tidak menghasilkan arus kas yang cukup untuk memenuhi pengeluaran.

\section{c. Insolvency}

1) Technical insolvency, merupakan kondisi dimana perusahaan tidak mampu memenuhi kewajibannya yang jatuh tempo sebagai akibat dari ketidakcukupan arus kas.

2). Insolvency in Bancrupty Sense, merupakan kondisi dimana total kewajiban lebih besar dari nilai pasar total aset perusahaan.Dan karena itu memiliki ekuitas yang negatif.

\section{d. Legal Bankruptcy}

Sebuah bentuk formal kebangkrutan dan telah disahkan secara hukum. Maka dapat disimpulkan financial distress adalah keadaan perusahaan yang memiliki potensi untuk mengalami kebangkrutan karena perusahaan tidak mampu membayar kewajiban-kewajibannya, menghasilkan laba kecil dan berpengaruh pada perubahan modal yang kemudian berlarut- larut hingga kondisi keuangan perusahaan makin memburuk sehingga diperlukan adanya restrukturisasi pada perusahaan yang bersangkutan.

Prediksi financial distress mempunyai manfaat yang cukup penting bagi segala pihak pelaku bisnis, dimana manfaat bagi pelaku bisnis dalam Jurnal Penelitian Almilia dan Kristijadi (2003) ditelaah dari pihak-pihak yang menggunakan model prediksi financial distress adalah sebagai berikut:

1. Pemberi pinjaman. Penelitian berkaitan dengan prediksi financial distress mempunyai relevansi terhadap institusi pemberi pinjaman, baik dalam memutuskan apakah akan memberikan suatu pinjaman dan menentukan kebijakan untuk mengawasi pinjaman yang telah diberikan.

2. Investor. Model prediksi financial distress dapat membantu investor ketika akan menilai kemungkinan masalah suatu perusahaan dalam melakukan pembayaran kembali pokok dan bunga.

3. Pembuat peraturan. Lembaga regulator mempunyai tanggung jawab mengawasi kesanggupan membayar hutang dan menstabilkan perusahaan individu, hal ini menyebabkan perlunya suatu 
model yang aplikatif untuk mengetahui kesanggupan perusahaan membayar hutang dan menilai stabilitas perusahaan.

4. Pemerintah. Prediksi financial distress juga penting bagi pemerintah dalam antitrust regulation.

5. Auditor. Model prediksi financial distress dapat menjadi alat yang berguna bagi auditor dalam membuat penilaian going concern suatu perusahaan.

6. Manajemen. Apabila perusahaan mengalami kebangkrutan maka perusahaan akan menanggung biaya langsung (fee akuntan dan pengacara) dan biaya tidak langsung (kerugian penjualan atau kerugian paksaan akibat ketetapan pengadilan). Sehingga dengan adanya model prediksi financial distress diharapkan perusahaan dapat menghindari kebangkrutan dan otomatis juga dapat menghindari biaya langsung dan tidak langsung dari kebangkrutan.

Berdasarkan fenomena aktual tersebut terlihat jelas pentingnya Early Warning untuk mengetahui kondisi perusahaan saat ini dan yang akan datang melalui prediksi financial distress dengan pengaplikasian atau penggunaan model analisis yang sesuai dan akurat, sehingga dapat diambil kebijakan atau keputusan yang cepat dan tepat agar perusahaan dapat survive dengan perubahanperubahan yang ada. Dengan demikian, tujuan dari penelitian ini adalah untuk mengetahui gejala masalah keuangan pada perusahaan jasa transportasi laut yang terdaftar di Bursa Efek Indonesia. Selain itu untuk mengetahui ada tidaknya potensi financial distress perusahaan jasa transportasi laut di Indonesia yang terdaftar di Bursa Efek Indonesia, serta untuk mengetahui hasil analisis pengaplikasian model Altman Z"-Emerging Market Score sebagai persiapan pada perusahaan jasa transportasi laut Indonesia. Penelitian ini diharapkan dapat memberikan masukan dan sumbangan berupa referensi ilmiah terhadap ilmu pengetahuan di bidang manajemen, khususnya bidang manajemen keuangan.

\section{Metode Penelitian}

Populasi yang digunakan dalam penelitian ini adalah perusahaan-perusahaan go public sektor jasa transportasi laut yang terdaftar di Bursa Efek Indonesia. Dalam penelitian ini yang menjadi sampel terpilih adalah perusahaan jasa transportasi yang terdaftar di Bursa Efek Indonesia yang memiliki laporan keuangan lengkap yang telah diaudit dari tahun 2018 - 2019. Tabel 1 menyajikan daftar perusahaan jasa transportasi yang dijadikan sampel penelitian adalah sebagai berikut:

Tabel 1. Sampel Penelitian

\begin{tabular}{|c|l|l|}
\hline NO & \multicolumn{1}{|c|}{ KODE } & \multicolumn{1}{c|}{ NAMA PERUSAHAAN } \\
\hline 1 & HITS & HUMPUSS INTERMODA TRANSPORTASI, TBK \\
\hline 2 & PTIS & INDO STRAITS, TBK \\
\hline 3 & RAJA & RUKUN RAHARJA, TBK \\
\hline 4 & SMDR & SAMUDERA INDONESIA, TBK \\
\hline 5 & TMAS & PELAYARAN TEMPURA EMAS, TBK. \\
\hline 6 & KARW & ICTSI JASA PRIMA, TBK \\
\hline
\end{tabular}

Sumber : Bursa Efek Indonesia dan ICMD

Jenis data yang digunakan adalah data sekunder yang diperoleh dari Bursa Efek Indonesia dan Indonesian Capital Market Dictionary (ICMD). Sedangkan metode pengumpulan data dilakukan dengan cara observasi pada perusahaan-perusahan jasa transportasi laut yang terdaftar di Bursa Efek Indonesia dengan laporan keuangan yang lengkap periode 2018 - 2019 dan dokumentasi jurnal kepustakaan yang terkait dengan prediksi financial distress. Dengan data pendukung daftar pustaka yang dipergunakan dalam memperkuat dalam analisis penelitian ini dipelajari dan dikaji pula literatur-literatur penelitian terdahulu, buku-buku pustaka, pencarian informasi dengan media elektonik, media sosial dan sumber-sumber lainnya yang berhubungan dengan bidang yang diteliti. 


\section{Pengukuran}

\section{Likuiditas (Modal Kerja / Total Aktiva)}

Modal Kerja dihitung dengan mengurangkan hutang jangka pendek saat ini dari kas dan setara kas. Jika sebuah perusahaan menghasilkan keuntungan, modal kerja akan tumbuh, kecuali jika mereka memberikan semua keuntungan (misalnya, kepada pemegang saham mereka).

\section{Profitabilitas (Laba Ditahan/ Total Aktiva)}

Laba ditahan adalah jumlah dari semua keuntungan yang diperoleh di masa lalu yang tersedia untuk diinvestasikan kembali di perusahaan. Ini mengacu pada total laba dikurangi dividen dan pajak. Perusahaan di pasar negara berkembang biasanya memiliki laba ditahan yang lebih sedikit, karena sebagian besar perusahaan di pasar ini memiliki waktu lebih sedikit untuk mengumpulkan laba ditahan.

\section{Rentabilitas Ekonomi (Laba Sebelum Bunga Pajak / TotalAktiva)}

Penghasilan perseroan pada tahun buku tertentu, sebelum pelunasan pajak dan bunga. Karena pajak dan bunga dapat mempengaruhi pendapatan secara positif atau negatif dan dapat menghasilkan keuntungan satu kali, mereka harus diabaikan dalam Model Z-Score altman.

\section{Laverage (Nilai Buku Ekuitas / Total Utang)}

Jumlah hutang dapat dikumpulkan dari neraca. Baik utang jangka panjang maupun jangka pendek merupakan bagian dari parameter ini. Cadangan, yang juga ada di sisi kredit neraca, bukan bagian dari parameter ini.

\section{Financial Distress}

Tingkat kesulitan keuangan perusahaan, diklasifikasikan menjadi kondisi financial distress, kondisi rawan, dan sehat.

\section{Pengembangan Hipotesis}

Kinerja merupakan salah satu indikator yang penting dalam menunjukkan apakah perusahaan atau organisasi tersebut berjalan baik atau buruk. Dengan mengetahui kinerja, maka secara tidak langsung kita dapat melihat kondisi perusahaan atau organisasi sebenarnya. Dalam hal ini kinerja keuangan perusahaan dapat kita lihat dari laporan keuangan yang dikeluarkannya, dimana dalam laporan keuangan kita dapat mengetahui informasi mengenai perusahaan tersebut dan dapat melihat kondisi keuangan perusahaan dengan jelas.

Dalam penelitian ini, kinerja keuangan pada perusahaan jasa transportasi laut yang terdapat pada Bursa Efek Indonesia dapat diketahui gejala masalah keuangan masing-masing emitennya melalui empat rasio keuangan Altman Z"- Emerging Market Score yang terdiri atas rasio likuiditas (Working capital ratio to Total Asset), rasio profitabilitas (Retained earning to Total Asset), rasio rentabilitas ekonomi (Earnings before interest and tax / EBIT to Total Asset) dan rasio leverage (Book value of equity to Total Liabilities) dan dari empat rasio keuangan Altman tersebut dengan mengaplikasikan model Altman Z"-Emerging Market Score dapat digunakan untuk memprediksi Financial Distress sehingga dari hasil analisis pengaplikasian model Altman Z" - Emerging Market Score tersebut dapat digunakan sebagai persiapan dalam membuat keputusan manajemen untuk menghadapi segala perubahan yang ada.

H1 = Diduga kinerja keuangan pada Perusahaan Transportasi Laut yang terdaftar di Bursa Efek Indonesia cenderung tidak baik. 
H2 = Diduga kinerja keuangan pada Perushaan Transportasi Laut yang terdaftar di Bursa Efek Indonesia cenderung akan mengalami kondisi financial distress

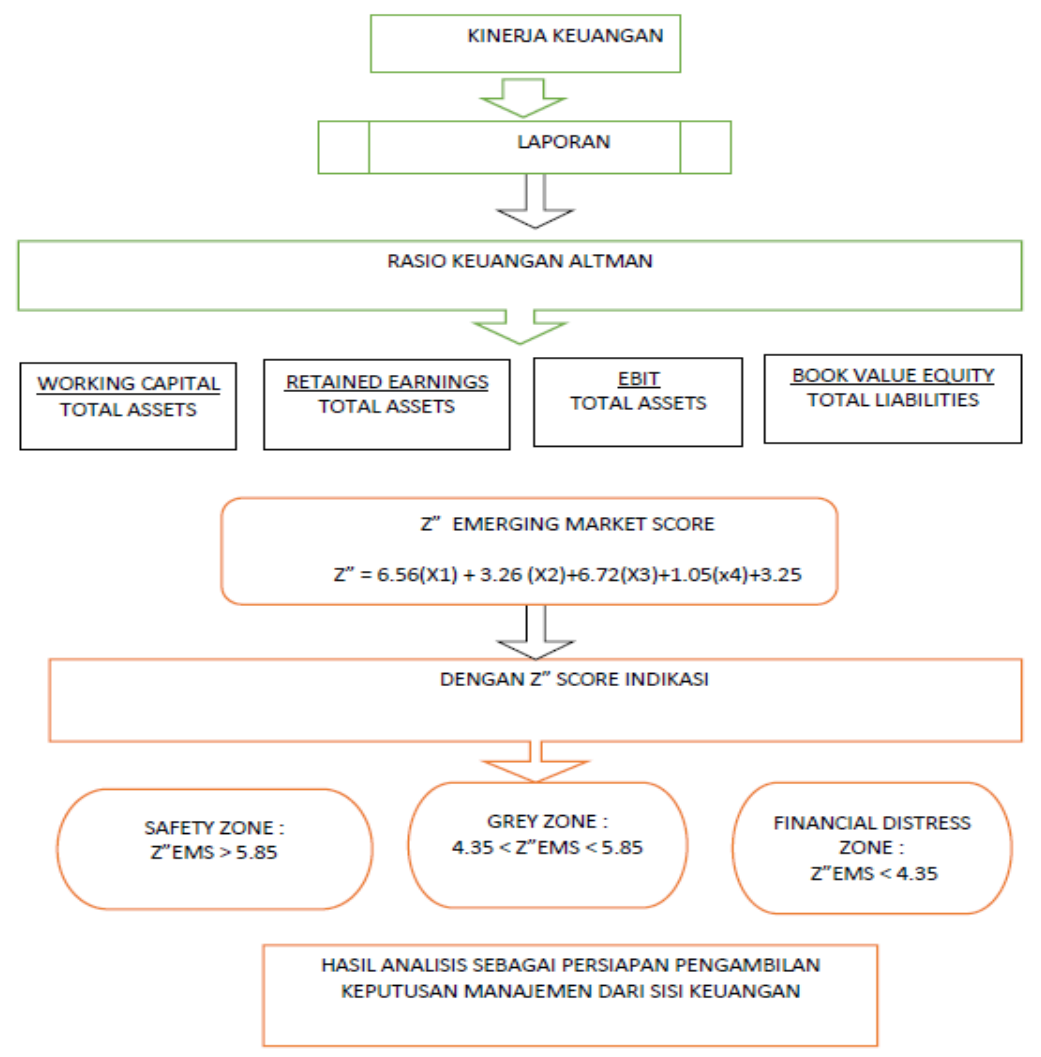

Gambar 1. Model Penelitian

(Sumber : data primer )

Pada gambar 1, memberikan suatu gambaran model penelitian atau sistematika penelitian terhadap perusahaan transportasi laut, yang mana pada hasil akhirnya dapat dianalisis sebagai persiapan pengambilan keputusan manajemen dari sisi keuangan.

\section{Model Altman Z" - Emerging Market Score}

Pada Emerging Market Review 6 (2005) dengan judul“An Emerging Market Credit Scoring System for For Corporate Bonds" oleh Edward I.Altman, Altman memaparkan bahwa semakin berkembangnya pertumbuhan ekonomi dengan karakter dan keunikan masing-masing negara dibutuhkan penyesuaian agar model $Z$ - Score ini dapat diaplikasikan menyeluruh ke seluruh dunia maka Altman menelaah ulang model Altman Z"-Score modifikasi keduanya (Z"- Score Modifikasi 1995) melalui penelitian lebih lanjut dan kemudian terciptalah Model Z'-Emerging Market Score ini, dimana model ini sesuai dengan penamaannya di aplikasikan untuk Negara-negara emerging market, yaitu negara-negara yang belum dikatakan maju (Less developed countries atau under developed countries) tetapi memiliki kondisi perekonomian yang bagus dan memiliki level of income antara low sampai middle, dimana Indonesia termasuk salah satu diantaranya menurut Morgan Stanley Capital International (MSCI). 
Terkait dengan sample perusahaan jasa transportasi laut yang terdapat di Bursa Efek Indonesia, dimana seperti diuraikan diatas berdasarkan emerging market index yang dikeluarkan oleh Morgan Stanley,bahwa Indonesia termasuk salah satu Negara emerging market maka model Z"Emerging Market Score ini yang akan di aplikasikan pada sample untuk mengetahui prediksi financial distressnya.

Model persamaan diskriminan Altman Z"-Emerging Market Score dinyatakan dengan Persamaan ... (nomor persamaan):

$Z^{\prime \prime}-\mathrm{EMS}=6.56 \mathrm{X} 1+3.26 \mathrm{X} 2+6.72 \mathrm{X} 3+1.05 \mathrm{X} 4+3.25$

(1)

Dimana:

$\mathrm{X} 1$ = Work Capital (Current Asset-Current Liabilities) / Total Assets

$\mathrm{X} 2$ = Retained Earnings / Total Assets

$\mathrm{X} 3$ = Earnings Before Interest and Taxes / Total Asset

X4 = Book Value of Equity / Total Liabilities

3.25 = A scale factor that equates 0 to a benchmark typical of other corporations that have defaulted on their corporated bonds

Dengan Z"-Score Indikasi:

Z" - EMS > 5.85 Area Sehat/ healthy area

$4.35<\mathrm{Z}$ "- EMS <5.85 Area Abu-abu / grey area (kondisi Rawan)

Z" - EMS <4.35 Area Financial Distress

\section{Hasil dan Pembahasan}

\section{Analisis Model Z" Emerging Market System Altman}

Tabel 2

Z" EMS PT. Humpuss Intermoda Transportasi, Tbk

\begin{tabular}{|c|c|c|c|c|c|c|}
\hline Koefisien & Variabel & 2018 & 2019 & $\begin{array}{c}\text { A scale factor that equates } \\
\text { o to a benchmark typical } \\
\text { of other corporations that } \\
\text { have defaulted on their } \\
\text { corporated bonds }\end{array}$ & $\begin{array}{l}\text { Z Score } \\
2018\end{array}$ & $\begin{array}{c}\text { Z Score } \\
2019\end{array}$ \\
\hline 6,56 & $\begin{array}{c}\mathrm{X} 1 \\
\text { (WCTA) }\end{array}$ & - 0,03432 & - & 3,25 & \multirow{4}{*}{$\begin{array}{c}\text { 4,9229 } \\
\text { (grey/rawan) }\end{array}$} & \multirow{4}{*}{$\begin{array}{l}5,0299 \\
\text { (grey/rawan) }\end{array}$} \\
\hline 3,26 & $\begin{array}{c}\mathrm{X} 2 \\
\text { (RETA) }\end{array}$ & 0,09579 & 0,13864 & 3,25 & & \\
\hline 6,72 & $\begin{array}{c}\mathrm{X} 3 \\
\text { (EBITTA) }\end{array}$ & 0,17775 & 0,18817 & 3,25 & & \\
\hline 1,05 & $\begin{array}{c}\mathrm{X} 4 \\
\text { (BVETL) }\end{array}$ & 0,37043 & 0,44664 & 3,25 & & \\
\hline
\end{tabular}

Sumber : Hasil pengolahan data

Pada tabel 2, merupakan perhitungan skor berdasarkan model Z Emerging Market Skor pada PT. Humpuss Intermoda Transportasi periode 2018-2019. Dari hasil perhitungan Z score Emerging Market, maka diperoleh nilai Z Score sebesar 4,9229 yang artinya untuk tahun 2018 PT. Humpuss Intermoda Transportasi, Tbk dalam keadaan grey (rawan), sedangkan untuk tahun 2019 telah diperoleh nilai Z Score sebesar 5,0299 yang mengindikasikan bahwa perusahaan masih dalam kondisi grey (rawan). 
Tabel 3

Z" EMS PT. Indo Straits, Tbk

\begin{tabular}{|c|c|c|c|c|c|c|}
\hline Koefisien & Variabel & 2018 & 2019 & $\begin{array}{l}\text { A scale factor that equates } \\
0 \text { to a benchmark typical of } \\
\text { other corporations that } \\
\text { have defaulted on their } \\
\text { corporated bonds }\end{array}$ & $\begin{array}{c}\text { Z Score } \\
2018\end{array}$ & $\begin{array}{c}\text { Z Score } \\
2019\end{array}$ \\
\hline 6,56 & $\begin{array}{c}\mathrm{X} 1 \\
\text { (WCTA) }\end{array}$ & $\begin{array}{l} \\
0,04280\end{array}$ & 0,18022 & 3,25 & \multirow{4}{*}{$\begin{array}{c}3,8277 \\
\text { (financial } \\
\text { distress) }\end{array}$} & \multirow{4}{*}{$\begin{array}{l}12,2589 \\
\text { (healthy } \\
\text { area) }\end{array}$} \\
\hline 3,26 & $\begin{array}{c}\mathrm{X} 2 \\
\text { (RETA) }\end{array}$ & 0,00818 & $\begin{array}{l}- \\
0,02163\end{array}$ & 3,25 & & \\
\hline 6,72 & $\begin{array}{c}\mathrm{X} 3 \\
\text { (EBITTA) }\end{array}$ & 0,00455 & 0,00025 & 3,25 & & \\
\hline 1,05 & $\begin{array}{c}\mathrm{X} 4 \\
\text { (BVETL) }\end{array}$ & 0,76320 & 7,51965 & 3,25 & & \\
\hline
\end{tabular}

Sumber : Hasil pengolahan data

Pada tabel 3, merupakan perhitungan skor berdasarkan model Z Emerging Market Skor pada PT. Indo Straits periode 2018-2019. Dari hasil perhitungan Z score Emerging Market, maka diperoleh nilai Z Score sebesar 3,8277 yang artinya untuk tahun 2018 PT. Indo Straits, Tbk dalam keadaan financial distress, sedangkan untuk tahun 2019 telah diperoleh nilai Z Score sebesar 12,2589 yang mengindikasikan bahwa perusahaan dalam kondisi yang sangat baik yaitu pada zona healthy area.

Tabel 4

Z” EMS PT. Rukun Raharja, Tbk

\begin{tabular}{|c|c|c|c|c|c|c|}
\hline Koefisien & Variabel & 2018 & 2019 & $\begin{array}{c}\text { A scale factor that equates } \\
0 \text { to a benchmark typical of } \\
\text { other corporations that } \\
\text { have defaulted on their } \\
\text { corporated bonds }\end{array}$ & $\begin{array}{c}\text { Z Score } \\
2018\end{array}$ & $\begin{array}{c}\text { Z Score } \\
2019\end{array}$ \\
\hline 6,56 & $\begin{array}{c}\mathrm{X} 1 \\
\text { (WCTA) }\end{array}$ & 0,25659 & 0,26199 & 3,25 & \multirow{4}{*}{$\begin{array}{c}8,6658 \\
\text { (healthy } \\
\text { area) }\end{array}$} & \multirow{4}{*}{$\begin{array}{c}7,5845 \\
\text { (healthy } \\
\text { area) }\end{array}$} \\
\hline 3,26 & $\begin{array}{c}\mathrm{X} 2 \\
\text { (RETA) }\end{array}$ & 0,26742 & 0,01460 & 3,25 & & \\
\hline 6,72 & $\begin{array}{c}\text { X3 } \\
\text { (EBITTA) }\end{array}$ & 0,07885 & 0,05105 & 3,25 & & \\
\hline 1,05 & $\begin{array}{c}\text { X4 } \\
\text { (BVETL) }\end{array}$ & 2,22001 & 2,12511 & 3,25 & & \\
\hline
\end{tabular}

Sumber : Hasil pengolahan data

Pada tabel 4, merupakan perhitungan skor berdasarkan model Z Emerging Market Skor pada PT. Rukun Raharja periode 2018-2019. Dari hasil perhitungan Z score Emerging Market, maka diperoleh nilai Z Score sebesar 8,6658 yang artinya untuk tahun 2018 PT. Rukun Raharja, Tbk dalam keadaan healthy area, sedangkan untuk tahun 2019 telah diperoleh nilai Z Score sebesar 7,5845 yang mengindikasikan bahwa perusahaan masih dalam kondisi healthy area.

Tabel 5

Z” EMS PT. Samudera Indonesia, Tbk 


\begin{tabular}{|c|c|c|c|c|c|c|}
\hline Koefisien & Variabel & 2018 & 2019 & $\begin{array}{l}\text { A scale factor that equates } \\
\text { O to a benchmark typical of } \\
\text { other corporations that } \\
\text { have defaulted on their } \\
\text { corporated bonds }\end{array}$ & $\begin{array}{c}\text { Z Score } \\
2018\end{array}$ & $\begin{array}{c}\text { Z Score } \\
2019\end{array}$ \\
\hline 6,56 & $\begin{array}{c}\mathrm{X} 1 \\
\text { (WCTA) }\end{array}$ & 0,26537 & 0,09134 & 3,25 & \multirow{4}{*}{$\begin{array}{c}6,6950 \\
\text { (healthy } \\
\text { area) }\end{array}$} & \multirow{4}{*}{$\begin{array}{l}3,7127 \\
\text { (financial } \\
\text { distress) }\end{array}$} \\
\hline 3,26 & $\begin{array}{c}\mathrm{X} 2 \\
\text { (RETA) }\end{array}$ & 0,01236 & - 0,11642 & 3,25 & & \\
\hline 6,72 & $\begin{array}{c}\mathrm{X} 3 \\
\text { (EBITTA) }\end{array}$ & 0,08418 & 0,10644 & 3,25 & & \\
\hline 1,05 & $\begin{array}{c}\mathrm{X} 4 \\
\text { (BVETL) }\end{array}$ & 1,04596 & 0,91279 & 3,25 & & \\
\hline
\end{tabular}

Sumber : Hasil pengolahan data

Pada tabel 5, merupakan perhitungan skor berdasarkan model Z Emerging Market Skor pada PT. Samudera Indonesia periode 2018-2019. Dari hasil perhitungan Z score Emerging Market, maka diperoleh nilai Z Score sebesar 6,6950 yang artinya untuk tahun 2018 PT. Samudera Indonesia, Tbk dalam keadaan healthy area, sedangkan untuk tahun 2019 telah diperoleh nilai Z Score sebesar 3,7127 yang mengindikasikan bahwa perusahaan sedang dalam kondisi yang tidak baik yaitu pada zona financial distress.

Tabel 6

Z” EMS PT. ICTSI Jasa Prima

\begin{tabular}{|c|c|c|c|c|c|c|}
\hline Koefisien & Variabel & 2018 & 2019 & $\begin{array}{l}\text { A scale factor that equates } \\
\text { O to a benchmark typical of } \\
\text { other corporations that } \\
\text { have defaulted on their } \\
\text { corporated bonds }\end{array}$ & $\begin{array}{c}\text { Z Score } \\
2018\end{array}$ & $\begin{array}{c}\text { Z Score } \\
2019\end{array}$ \\
\hline 6,56 & $\begin{array}{c}\mathrm{X} 1 \\
\text { (WCTA) }\end{array}$ & 2,08835 & $-\overline{2,46036}$ & 3,25 & \multirow{4}{*}{$\begin{array}{c}-19,4664 \\
\text { (financial } \\
\text { distress) }\end{array}$} & \multirow{4}{*}{$\begin{array}{l}-24,1431 \\
\text { (financial } \\
\text { distress) }\end{array}$} \\
\hline 3,26 & $\begin{array}{c}\mathrm{X} 2 \\
\text { (RETA) }\end{array}$ & $\begin{array}{l} \\
2,66047\end{array}$ & $\begin{array}{l} \\
3,19828\end{array}$ & 3,25 & & \\
\hline 6,72 & $\begin{array}{c}\mathrm{X} 3 \\
\text { (EBITTA) }\end{array}$ & 0,03834 & $\begin{array}{l}- \\
0,02632\end{array}$ & 3,25 & & \\
\hline 1,05 & $\begin{array}{c}\text { X4 } \\
\text { (BVETL) }\end{array}$ & $\begin{array}{c}- \\
0,57269\end{array}$ & $\overline{0}, 61896$ & 3,25 & & \\
\hline
\end{tabular}

Sumber : Hasil pengolahan data

Pada tabel 6, merupakan perhitungan skor berdasarkan model Z Emerging Market Skor pada PT. ICTSI Jasa Prima periode 2018-2019. Dari hasil perhitungan Z score Emerging Market, maka diperoleh nilai Z Score sebesar -19,4664 yang artinya untuk tahun 2018 PT. ICTSI Jasa Prima, Tbk dalam keadaan financial distress, begitu juga untuk tahun 2019 telah diperoleh nilai Z Score sebesar 24,1431 yang mengindikasikan bahwa perusahaan masih dalam kondisi yang sangat tidak baik yaitu pada zona financial distress.

Tabel 7

Z" EMS PT. Pelayaran Tempura Emas 


\begin{tabular}{|c|c|c|c|c|c|c|}
\hline Koefisien & Variabel & 2018 & 2019 & $\begin{array}{l}\text { A scale factor that equates } \\
\text { O to a benchmark typical of } \\
\text { other corporations that } \\
\text { have defaulted on their } \\
\text { corporated bonds }\end{array}$ & $\begin{array}{c}\text { Z Score } \\
2018\end{array}$ & $\begin{array}{c}\text { Z Score } \\
2019\end{array}$ \\
\hline 6,56 & $\begin{array}{c}\mathrm{X} 1 \\
\text { (WCTA) }\end{array}$ & 0,00009 & 0,33142 & 3,25 & \multirow{4}{*}{$\begin{array}{c}\mathbf{3 , 8 8 5 7} \\
\text { (financial } \\
\text { distress) }\end{array}$} & \multirow{4}{*}{$\begin{array}{l}3,8472 \\
\text { (financial } \\
\text { distress) }\end{array}$} \\
\hline 3,26 & $\begin{array}{c}\mathrm{X} 2 \\
\text { (RETA) }\end{array}$ & 0,0001 & 0,0001 & 3,25 & & \\
\hline 6,72 & $\begin{array}{c}\mathrm{X} 3 \\
\text { (EBITTA) }\end{array}$ & 0,000001 & 0,00005 & 3,25 & & \\
\hline 1,05 & $\begin{array}{c}\text { X4 } \\
\text { (BVETL) }\end{array}$ & 0,60487 & 0,56801 & 3,25 & & \\
\hline
\end{tabular}

Sumber : Hasil pengolahan data

Pada tabel 7, merupakan perhitungan skor berdasarkan model Z Emerging Market Skor pada PT. Pelayaran Tempura Emas periode 2018-2019. Dari hasil perhitungan Z score Emerging Market, maka diperoleh nilai Z Score sebesar 3,8857 yang artinya untuk tahun 2018 PT. Pelayaran Tempura Emas, Tbk dalam keadaan financial distress, begitu juga untuk tahun 2019 telah diperoleh nilai Z Score sebesar 3,8472 yang mengindikasikan bahwa perusahaan masih dalam kondisi yang sangat tidak baik yaitu pada zona financial distress.

Berdasarkan nilai Z Score secara keseluruhan pada enam perusahaan transportasi laut periode 2018-2019, telah diperoleh rata-rata keseluruhan yaitu sebesar 1,40177. Hal ini mengindikasikan bahwa perusahaan dalam kondisi financial distress.

Tabel 8

Nilai Z" EMS Keseluruhan

\begin{tabular}{|c|c|c|c|c|c|c|c|}
\hline \multirow{2}{*}{ No } & \multirow{2}{*}{$\begin{array}{l}\text { Kode } \\
\text { Persh }\end{array}$} & \multicolumn{4}{|c|}{ Rata-rata periode 2018-2019 } & \multirow{2}{*}{$\begin{array}{c}\text { Nilai Z } \\
\text { Score }\end{array}$} & \multirow{2}{*}{$\begin{array}{l}\text { Prediksi } \\
\text { Kondisi }\end{array}$} \\
\hline & & WCTA & RETA & EBITTA & BVETL & & \\
\hline 1 & HITS & $-0,04807$ & 0,117215 & 0,18296 & 0,408535 & 4,9764 & Grey \\
\hline 2 & PTIS & 0,06871 & $-0,00672$ & 0,0024 & 4,141425 & 3,8278 & $\begin{array}{r}\text { Financial } \\
\text { distress }\end{array}$ \\
\hline 3 & RAJA & 0,25929 & 0,14101 & 0,06495 & 2,17256 & 8,1252 & $\begin{array}{c}\text { Healthy } \\
\text { area }\end{array}$ \\
\hline 4 & SMDR & 0,17835 & $-0,05203$ & $-0,01113$ & 0,979375 & 5,2039 & Grey \\
\hline 5 & KARW & $-2,27435$ & $-2,92937$ & 0,00601 & $-0,59582$ & $-21,8047$ & $\begin{array}{r}\text { Financial } \\
\text { distress }\end{array}$ \\
\hline 6 & TMAS & 0,00008 & 0,00001 & 0,000025 & 0,58644 & 3,8664 & $\begin{array}{r}\text { Financial } \\
\text { distress }\end{array}$ \\
\hline \multicolumn{2}{|c|}{ Rata-rata } & $-0,302665$ & $-0,45498$ & 0,04086 & 1,28208 & 1,40177 & $\begin{array}{r}\text { Financial } \\
\text { distress }\end{array}$ \\
\hline
\end{tabular}

Sumber : Hasil pengolahan data

Pada tabel 8, memberikan penjelasan mengenai nilai Z" EMS secara keseluruhan dari keenam perusahaan pada periode 2018-2019 yang dilengkapi dengan prediksi kondisi perusahaan bahwa apakah perusahaan dalam kondisi sehat, rawan, atau financial distress.

Berdasarkan data perusahaan transportasi laut secara keseluruhan periode 2018-2019, telah diperoleh rata-rata secara menyeluruh bahwa nilai working capital to total asset adalah negative yaitu sebesar $-0,302665$, nilai retained earnings to total asset adalah negative yaitu sebesar -0,45498, nilai earning before interest and tax to total asset adalah positif yaitu sebesar 0,04086, dan nilai book value of equity to total liabilities adalah positif yaitu sebesar 1,28208. Dengan demikian telah diperoleh nilai 
rata-rata Z"EMS dari keenam perusahaan yaitu sebesar 1,40177 yang mengindikasikan bahwa kondisi perusahaan mengalami financial distress secara dominan. Hanya satu perusahaan yang berada pada zona healthy area, yaitu PT. Rukun Raharja, Tbk, kemudian ada dua perusahaan yang berada pada zona grey (rawan) yaitu pada PT. Humpuss Intermoda Transportasi, Tbk dan PT. Samudera Indonesia, Tbk. Sedangkan tiga perusahaan lainnya mengalami financial distress yaitu pada PT. Indo Straits, Tbk, PT. ICTSI Jasa Prima, Tbk, dan PT. Pelayaran Tempura Emas, Tbk.

Dari hasil analisa rasio keuangan secara keseluruhan, terbukti bahwa perusahaan yang dianalisis cukup berpotensi mengalami financial distress. Hal ini dikarenakan beberapa score yang diperoleh nilainya tidak stabil bahkan negative hingga sangat jauh dari angka positif. Sehingga telah nampak gejala masalah keuangan dan mengakibatkan kondisi keuangan perusahaan menjadi terancam bangkrut. Untuk menghindari hal tersebut dapat dilakukan dengan cara meningkatkan aset likuid, menegosiasikan persyaratan yang lebih baik dengan pelanggan dan pemasok, menghentikan pengeluaran yang tidak perlu untuk menghemat pengeluaran perusahaan, dan menurunkan modal melalui pengurangan pembayaran dividen, meningkatkan penghasilan melalui pembayaran hutang dan dengan demikian mengurangi beban bunga yang sedang berlangsung.

Selain itu mengejar lini produk yang menguntungkan untuk meningkatkan pertumbuhan pendapatan jangka panjang, mengejar peluang dengan return yang tinggi atas asset, dan menghentikan kegiatan dengan hasil pengembalian aset yang rendah dan menggunakan uang tunai untuk membayar hutang, penurunan modal serta meningkatkan laba atas asset. Upaya lain yang dapat dilakukan yaitu mengkonversi hutang jangka panjang terhadap ekuitas atau lebih disarankan ekuitas tersebut jika diperlukan serta embuat keputusan bisnis jangka panjang yang baik sehingga akan nampak berpengaruh pada harga saham.

\section{Kesimpulan}

Kini perusahaan yang berada pada kondisi financial distress lebih dominan, dan lainnya juga berpotensi mengalami financial distress. Hanya satu perusahaan yang berada pada kondisi keuangan yang sehat yaitu PT. Rukun Raharja, Tbk. Sehingga, perusahaan perlu meningkatkan dan memperbaiki kinerja keuangannya yaitu PT. Humpuss Intermoda Transportasi, Tbk, PT. Indo Straits, Tbk, PT. Samudera Indonesia, Tbk, PT. Pelayaran Tempura Emas, Tbk, dan khususnya pada PT. ICTSI Jasa Prima yang mengalami kondisi keuangan paling buruk. Jumlah sampel yang terbatas menjadi keterbatasan dalam penelitian ini serta belum sesuai target dikarenakan kurang lengkapnya data laporan keuangan yang diperoleh dari BEI. Penelitian ini memberikan rekomendasi terhadap perusahaan bahwa perusahaan perlu meningkatkan kinerja keuangan untuk memperbaiki kondisi keuangan yang mengalami financial distress. Sedangkan bagi investor, perlu memilih perusahaan yang berpotensi sehat dalam keuangannya ketika melakukan investasi sehingga tepat dalam menghasilkan profit yang diharapkan. Untuk agenda penelitian yang akan datang, penelitian ini masih bisa dikembangkan lagi dengan melakukan pengembangan model.

\section{Daftar Pustaka}

Altman, Edward I. (1968). financial ratios, discriminant analysis and the prediction of corporate bankruptcy, The Journal of Finance, vol 23, Issue 4.

Emery ,Douglas.R;Finnerty, John.D; Stowe, John.D. (2004). Corporate Financial Management. Pearson/Prentice Hall

Meeampol, Sasivimol dkk.2014. Applying Emerging Market Z-Score Model To Predict Bankruptcy:A Case Study Of Listed Companies In The Stock Exchange Of Thailand (SET). Riset.Kasetsart University, Thailand 
Mu-Yen Chen, (2011), Bankruptcy prediction in firms with statistical and intelligent techniques and a comparison of evolutionary computation approaches, Departemen of Information Management, National Taichung Institute of Technology,Taichung 404, Taiwan, ROC. Elsevier Ltd. All rights reserved

Myles, Coelho. (2014). Predicting Corporate Failure: an application of Altman's ZScore and Altman's EMS models to the JSE Alternative Exchange from 2008 to 2012, .Disertasi.University of Cape Town. South Africa.

Platt \& Platt. (2002). Journal of Economics and Finance Vol.26. no.2 Summer2002 "Predicting Corporate Financial Distress: Reflections on Choice-Based Sample Bias.

Springate, G. L. (1978). Predicting the Possibility of Failure in a Canadian Firm. Master of Business Administra-tion Project (Unpublished). Simon Fraser Univer-sity.

Suhartono, Anton. (2015). Setelah Indonesia, General Motors Tutup Pabrik di Rusia, Melalui (http://news.okezone.com/read/2015/03/19/15/1120860/ setelah-indonesia-general-motorstutup-pabrik-di-rusia)

Supardi dan Sri Mastuti. (2003). Validitas Penggunaan Z-Score Altman Untuk Menilai Kebangkrutan Pada Perusahaan Perbankan Go Publik Di Bursa Efek Jakarta. Dalam Kompak No. 7. JanuariApril 